\title{
The Effect of Product Demand on Inequality: Evidence from the US and the UK
}

\author{
By Marco Leonardi*
}

\begin{abstract}
Using Consumer Expenditure Survey data this paper shows that more educated workers demand more high-skill-intensive services and, to a lower extent, more very low-skill-intensive services (such as personal services). Additional evidence at the MSA level shows that this "education elasticity of demand"mechanism can explain part of the correlation between the share of college-educated workers in a city and the employment share of service industries. The parametrization of a simple model suggests that this induced demand shift can explain around $6.5 \%$ of the relative demand shift in the US between 1984 and 2002. Similar results are provided for the UK.

JEL: J21, J31

Keywords: Wage inequality, product demand, income elasticity
\end{abstract}

There is still some disagreement about the causes of the increase in wage inequality and in the college premium in the US and in the UK. Several reasons have been proposed to explain the shift in demand against low skilled workers, in particular skill-biased technical change, trade liberalization and changes in wage setting institutions, but none of these explanations seems to be exhaustive (Card and DiNardo 2002; Acemoglu 2002).

The recent literature on wage inequality has highlighted the phenomenon of "wage polarization". ${ }^{1}$ Together with a novel view of labor demand shifts, the literature on polarization has sparked a new debate on product demand shifts. On the one hand, models of unbalanced productivity growth generate second-round product demand effects - driven by changes in relative prices that depend on the elasticity of substitution between goods in consumption (Autor and Dorn 2013; Goos, Manning, and Salomons 2014). On the other hand, other models predict changes in relative product demand because preferences are non-homothetic or because educated workers substitute domestic chores for market-provided house-

* University of Milan and IZA, via Conservatorio 7, 20122 Milan, Italy, marco.leonardi@unimi.it. I would like to thank Daron Acemoglu, David Autor, Tito Boeri, Steve Machin, Enrico Moretti and all the participants to seminars at MIT, UC Berkeley, IZA, Humboldt Berlin, Luiss Rome, SOFI Stockholm University, the IAB-BIBB TASKS conference in Bonn and the ESSLE-CEPR conference at Ammersee. This paper is a substantial extension of a working paper which first appeared in 2003 (Leonardi, 2003). Part of this paper was written while I was visiting UC Berkeley whose hospitality is gratefully acknowledged. All remaining errors are mine.

${ }^{1}$ See Acemoglu and Autor (2011) for a review. This literature has looked at many countries: Autor, Katz and Kearney (2006 and 2008) and Autor and Dorn (2013) for the US; Goos and Manning (2007) for the UK; Spitz-Oener (2006) and Dustmann, Ludsteck and Schönberg (2009) for Germany; Goos, Manning, and Salomons (2009), Michaels, Natraj, and Van Reenen (2014) for Europe. 
hold services when income inequality rises (Manning 2004; Mazzolari and Ragusa 2013). There is, however, disagreement about the relative importance of these product demand effects in explaining changes in labor demand. Autor and Dorn (2013) and Goos, Manning, and Salomons (2014) look at employment shares in service occupations and find a limited impact of changes in product demand shifts, whereas Mazzolari and Ragusa (2013) argue that these effects are substantial.

This paper sheds some light on this discussion and assesses a mechanism which may explain part of the increase of wage inequality. If individuals with relatively higher education prefer to consume goods and services whose production is relatively skill intensive, then an increase in the relative supply of skilled labor can shift demand for final products and raise the relative demand for skills measured as the college premium. I refer to this mechanism as the "education elasticity of demand". 2 The time-series evidence is consistent with this hypothesis. Consumer Expenditure Survey data (reported in Table A1 in the online Appendix) show that the share of head of households with some college education went from $27.5 \%$ to $62 \%$ from 1972 through 2012. At the same time the share of total expenditure in the most skill-intensive services (defined as the sum of health services, education and personal insurance) rose from $14.4 \%$ in 1972 to $20.1 \%$ in 2012 while the combined share of expenditure on food and apparel (two low-skill-intensive products) declined from $26.1 \%$ in 1972 to $17.7 \%$ in 2012 .

The main idea is presented in a static general equilibrium model with two skill levels, two sectors producing two aggregate final goods (the high-skill-intensive and the low-skill-intensive), and non-homothetic preferences. The model relates the college premium to education elasticities of demand and assesses the importance of this mechanism on the basis of the estimates produced in the empirical part of the paper.

In the empirical part, I present two pieces of evidence of the "education elasticity of demand"mechanism, one at the economy-wide level and the second at the Metropolitan Statistical Area (MSA) level. Firstly, to translate the consumption patterns into changes in the skill composition of employment and into skilledunskilled relative wages, I combine micro data on consumption of 38 non-durable consumption goods and services from the Consumer Expenditure Survey (CEX) to data on industry skill composition from the Current Population Survey (CPS). The estimated education and income elasticities of each consumption item are then related to the skill intensity of the industries which manufacture the final consumption good or provide the final consumption service. The results indicate that on average educated consumers tend to favor skill-intensive goods and services: education, health and professional services have very large education and income elasticities. There is also a phenomenon of "consumption polariza-

\footnotetext{
${ }^{2}$ The focus of this paper is on education elasticities, however, as a complementary mechanism, income elasticities of demand may also favor skill-intensive products. For this reason I will often refer to nonhomothetic preferences. There is a long-standing macro literature on structural change due to nonhomothetic preferences which focuses on income effects but ignores different consumption preferences across education groups (Colin Clark 1957; Ngai and Pissarides 2007; Buera and Kaboski 2012).
} 
tion"i.e. very low-skill-intensive services like food preparation, cleaning, repair services also have large elasticities (although to a lower extent than high-skillintensive services) and give rise to a J-shaped relationship between estimated elasticities and industry skill intensities. This J-shape remains significant when Input-Output tables are used to account for the skill intensity of intermediate inputs. Furthermore, and suggesting a general validity of this mechanism, I show some evidence in the same direction for the UK using Family Expenditure Survey (FES) consumption data matched to Labor Force Survey (LFS) data.

The second piece of evidence tests the implications of the theoretical model for industry employment shares using variation across MSAs and over time in US Census data. The J-shaped relationship between elasticities and skill intensities implies a positive product demand effect for both high-skill-intensive and very low-skill-intensive industry shares. Therefore an exogenous increase in one MSA's skill supply (measured as the skill ratio $H / L$ ) should raise the employment share of high-skill-intensive nontradable industries with high education elasticities both through a supply and a product demand effect. While the effect of demand can be detected at the MSA level only for nontradables which have a local demand, the change in $H / L$ at the MSA level is instrumented using changes in $H / L$ in tradable industries at the national level projected on the MSA's industrial composition in 1980. Consistent with the model predictions, I find a positive correlation between employment share growth and education elasticities in nontradable skill-intensive industries where both the product demand effect and the supply effect are positive. On the contrary, for the nontradable low-skill-intensive industries, the correlation is ambiguous because the supply effect is negative.

Finally, to establish the quantitative importance of income and education elasticities in accounting for the rise of the nation-wide college premium, I parametrize the static general equilibrium model using the estimates of the relevant elasticities and of labor market aggregates of the US and UK economy. The results indicate that this consumption mechanism can explain about $6.5 \%$ of the total shift in relative labor demand in the US and a similar proportion of the total shift in the UK. These results indicate that product demand shifts are not large (although they are relevant) as claimed by Autor and Dorn (2013) and Goos, Manning, and Salomons (2014).

This paper contributes to the debate on the importance of demand shifts in the wage polarization literature matching data on consumption to data on industry skill intensity. The only previous paper which looks explicitly at changes in product demand using consumption data is Mazzolari and Ragusa (2013) but it is limited to consumption of low-skill-intensive services and does not focus on education elasticities.

The second novel contribution consists in the investigation of the extent to which exogenous changes in the composition of skills at the MSA level feed back into higher employment shares of nontradable industries through the "education elasticity" channel. This empirical evidence at the MSA level is related to the 
literature on local multipliers (Moretti 2010). According to this literature an exogenous increase in the number of jobs in the tradable sector in a city results in an increase in local labor demand in the service sector. This paper adds the explicit account of education elasticities to the argument that positive demand shocks in the tradable sector have large multiplier effects on the nontradable sector: I show that the effect of a shock is larger in nontradable sectors that provide services with a high education elasticity of consumption.

This paper is also related to the early literature on inequality because product demand shifts due to consumption preferences are part of between-sector shifts. That literature (Katz and Murphy 1992; Berman, Bound, and Griliches 1994; Berman, Bound, and Machin 1998) found that large part of skill-upgrading and of the increase in wage inequality occurred mainly within sectors rather than between sectors but never explicitly investigated the role of product demand shifts. In this paper I attempt to estimate the contribution of this mechanism to the overall increase in the college premium in the US and UK.

The plan of the paper is as follows. In Section I, I present the basic model whose details are in Appendix A at the end of the paper. The evidence on the relationship between elasticities and skill intensities is described in Section II, while Section III looks at the evidence on industry employment shares within cities (MSAs). Both these sections are divided in subsections which describe the data, the empirical strategy and the results. In Section IV, I quantify the contribution of education and income elasticities in explaining the shift in relative labor demand. The interpretation of the results and the conclusions are in Section V. An online Appendix collects the details on sample selection and the tables of descriptive statistics of the many datasets used.

\section{The Model}

This model is meant as a guidance for the empirical part of the paper and provides a framework to quantify the importance of the income and education elasticities of product demand (see Section IV). It is a static general equilibrium model with two commodities $Y_{1}$ and $Y_{2}$ and workers/consumers of two education levels ( $H$ skilled workers/consumers with a college degree and $L$ unskilled workers/consumers without a college degree). Consumers' preferences vary across education group and are non-homothetic in income. In this Section I outline the main assumptions and describe the main predictions of the model. I refer to the Appendix A at the end of the paper for all the equations and the details.

The demand functions for the two commodities have a generic form:

$$
\begin{aligned}
p_{1} Y_{1} & =H y_{1}^{h}\left(\frac{p_{1}}{p_{2}}, w_{h}\right)+L y_{1}^{l}\left(\frac{p_{1}}{p_{2}}, w_{l}\right) \\
Y_{2} & =H y_{2}^{h}\left(\frac{p_{1}}{p_{2}}, w_{h}\right)+L y_{2}^{l}\left(\frac{p_{1}}{p_{2}}, w_{l}\right)
\end{aligned}
$$


where $\frac{p_{1}}{p_{2}}$ is the relative price of the skill-intensive commodity and $w_{h}\left(w_{l}\right)$ is the wage of skilled (unskilled) workers. Equation 1 denotes the total demand for the high-skill-intensive commodity $Y_{1}$ as the sum of demand by the $H$ skilled workers and by the $L$ unskilled workers. Equation 2 has the same interpretation for the low-skill-intensive commodity $Y_{2}$ and $p_{2}$ is normalized to one.

In this model there is a role for education elasticities because the per-capita demand functions for both high-skill and low-skill-intensive commodities $y_{1}^{i}($. and $y_{2}^{i}($.$) are assumed to depend from education i=h, l$. The hypothesis of the model (to be verified in the data) is that college-educated workers have different consumption preferences and may spend more on specific types of goods and services such as the education of their own children, health services, professional goods and services, books and newspapers. Skilled and unskilled workers are also allowed to have different income elasticities (preferences are non-homothetic and income elasticities may differ from unit value).

Using the equations above and market clearing, the elasticity of the skill premium with respect to the skill ratio can be written as: ${ }^{3}$

$$
\frac{d \log w_{h}}{d \log H}=\frac{\left(1-a_{2}\right)\left\{\left(\lambda_{H}-\lambda_{L}\right)\left[R_{1}-\left(1-R_{1}\right) \frac{H}{L}\right]-\left[1+\lambda_{H}+\frac{H}{L}\left(1+\lambda_{L}\right)\right]\right\}}{\left(\lambda_{L}+1\right) \sigma+\left(\lambda_{H}-\lambda_{L}\right)\left(1-a_{1}\right) \sigma-\left(\lambda_{H}-\lambda_{L}\right) T}
$$

where $T=\left\{R_{1}\left[\left(a_{1}-a_{2}\right) \varepsilon_{1 p}^{h}+\left(1-a_{2}\right) \varepsilon_{1 m}^{h}\right]+\left(1-R_{1}\right)\left[\left(a_{1}-a_{2}\right) \varepsilon_{1 p}^{l}-a_{2} \varepsilon_{1 m}^{l}\right]\right\}$. $R_{1}=\frac{H y_{1}^{h}(.)}{H y_{1}^{h}(.)+L y_{1}^{l}(.)}$ is the share of total expenditure that skilled workers spend on the high-skill-intensive commodity. $\varepsilon_{1 m}^{i}$ is the income elasticity of demand for the high-skill-intensive commodity, the index $i=h, l$ indicates that the elasticity is different for skilled and unskilled consumers. ${ }^{4} a_{1}, a_{2}$ are the wage bill shares of skilled labor in the two sectors, $\lambda_{H}$ and $\lambda_{L}$ are the ratios of skilled and unskilled labor and $\sigma$ is the elasticity of substitution (see Appendix A for details).

The model has two main predictions which I will test in the following empirical sections:

1) The main prediction of the model relates education and income elasticities to the change in the skill premium. The effect of education elasticities contributes to increase the skill premium through the term $R_{1}$. An increase in $\frac{H}{L}$ tends to increase wage inequality if skilled workers demand more of the

\footnotetext{
${ }^{3}$ Notice that this model improves on Katz and Murphy (1992) key equation $\log \frac{w_{h}}{w_{l}}=\alpha+\beta t+\gamma \log \frac{H}{L}$ adding the effect of elasticities. Unlike Acemoglu and Autor (2011) who explain wage polarization with three skill levels and task-replacing technological progress, the model in this paper cannot explain polarization. I use a model with two skill levels because a model with three skill levels would imply estimating consumption elasticities of workers with a mid level of education which are insignificantly different from other education groups' elasticities.

${ }^{4}$ Due to normalization, elasticities are in relative terms with respect to commodity 2 . The equation depends also from $\varepsilon_{1 p}^{i}$ however in this paper I consider education as the driving force of consumption preferences and I view prices as endogenous, therefore price elasticities will not be estimated in the benchmark specification in the empirical part. Other papers focus on price effects on wage inequality, for example Cortes (2008) and Moretti (2013).
} 
high-skill-intensive commodity than unskilled workers, i.e. $y_{1}^{h}()>.y_{1}^{l}(.) .^{5}$ The traditional income elasticity is distinct from the education elasticity and works within education groups. Income elasticities (which are typically positive) contribute to explain the rise of the skill premium reducing the denominator of Equation 3. If richer workers within both education groups tend to consume more of the skill-intensive commodity (i.e. $\varepsilon_{1 m}^{h}$ and $\varepsilon_{1 m}^{l}>1$ for both skilled and unskilled workers), then an increase in the average level of income (both $w_{l}$ and $w_{h}$ ) will also shift out the relative demand of the skill-intensive commodity and increase the college premium.

2) The second prediction of the model is for sectoral employment shares. The employment share of the skill-intensive sector is $e_{1}=\frac{H_{1}+L_{1}}{H+L}$. The effect of an increase in skill intensity $d \log H$ on $e_{1}$ is positive because of the concurrent supply and demand effects: the increase in the number of skilled workers will raise employment in the sector and in turn increase demand of the final commodity produced there. This prediction of the model will be tested in Section III, studying the relationship between changes in $H / L$ and industry employment shares within cities under the assumption that services cannot be traded outside the city-specific local labor market.

\section{Evidence on the Relationship between Elasticities and Skill Intensities}

In this section I test the first prediction of the model: the education elasticity of demand mechanism may explain part of the increase in the college premium only if more educated (and richer) consumers tend to consume more skill-intensive products and services. To test this hypothesis I first match consumption data to skill intensity data, then I regress estimated elasticities on skill intensities. For reasons of space, the details on sample selection and all tables of descriptive statistics of US and UK data used in this section (Tables A2 to A8) are in the online Appendix. The tables of results for the UK (Tables A10 and A11) are also in the online Appendix.

\section{A. The Match of Expenditure and Industry Skill Intensity Data}

The data on consumption are drawn from the CEX. A consistent dataset is available at NBER from 1984 to 2002 while data are available online at the Bureau of Labor Statistics through 2012. Since the purpose of the paper is to assess if education elasticities may explain part of the increase in the college premium in the US and UK, I select the time period between 1994 to 1997 in the mid of

\footnotetext{
${ }^{5}$ The term $R_{1}$ increases the numerator of Equation 3 if $R_{1}>\frac{H}{H+L}$ i.e. if $y_{1}^{h}()>.y_{1}^{l}($.$) . If educated and$ non-educated workers had the same demand for the high-skill-intensive commodity (i.e. $\left.y_{1}^{h}()=.y_{1}^{l}().\right)$, then $R_{1}=\frac{H}{H+L}$ and the term $\left(\lambda_{H}-\lambda_{L}\right)\left[R_{1}-\left(1-R_{1}\right) \frac{H}{L}\right]$ would disappear and the numerator of Equation 3 would then be unambiguously negative.
} 
the period of rapidly rising inequality and run robustness checks on other time periods in Section II.F and Table $3{ }^{6}$

I use data on all items whose consumption has been consistently recorded from 1994 to 1997 (38 items). I include in total expenditure housing rent but exclude own-property housing expenditures (property taxes, interest on house loans and housing intermediate goods) because they cannot be easily matched with an industry and vehicle purchase (whose income elasticity is very high given that this is an infrequent purchase). ${ }^{7}$ Total expenditure is the sum over the 38 items and represents $84 \%$ of total expenditure as provided by NBER. The final sample includes 23,268 households and their expenditure shares on 38 non-durable consumption items. The average age of the head of household is around 45 years, $52 \%$ of heads have at least some college education (defined as 13 or more years of education), $60 \%$ are males (see Table A2 in the online Appendix).

To assess whether more educated and richer consumers consume relatively more skill-intensive goods and services, I match the information on individual consumption items from the CEX to the skill intensity of the industry which produces the final good or service calculated from the CPS. For each matched industry in the CPS, I calculate two different measures of skill intensity: a raw measure and a measure which accounts for intermediate inputs (the results are in Table A3 and A4 in the online Appendix).

The first measure of industry skill intensity is the share of workers who attained some college education (defined as 13 or more years of schooling). To avoid potential reverse causality skill intensity is calculated on CPS data 1979-1980 and is predetermined to elasticities estimated in 1994-1997. Among low-skillintensive industries there are food products, eating and drinking places, apparel production, repair services, personal services, household supplies and household services. Among high-skill-intensive industries there are business and professional services, education, health and social services and financial services and insurance.

The second measure is adjusted for the skill intensity of intermediate inputs using Input-Output tables in year 1995 (the 3-digit industry code of the CPS is matched to the 123-industry Input-Output industry code in Table A5 in the online Appendix). I account for intermediate inputs because the 38 industries which have a direct match to a consumption item represent only about $57 \%$ of total employment in the US economy and input-producing industries may have a different skill intensity than those that produce the final output.

The input-adjusted skill intensity of final product $j$ is calculated as $z_{j}^{I N P U T}=$

\footnotetext{
${ }^{6}$ The data both in the US (Lemieux 2006; Autor, Katz, and Kearney 2008; Heathcote, Perri, and Violante 2010) and in the UK (Machin and VanReenen 2008; Blundell and Etheridge 2010) show that the growth of the college wage premium was rapid through the 1980s and the 1990s then it slowed down.

${ }^{7}$ The reason that durables are often excluded is that the system of Engel curves is derived on the basis of the utility flow from consumption which can be read straight from the expenditure only for nondurables. For durables in principle we need to impute a service flow from the stock and expenditures on durables. As a robustness check I include also vehicle purchase and own-property housing to reach $100 \%$ of expenditure: the results regarding education elasticities are qualitatively unaltered (results available upon request).
} 
$\sum_{i} \frac{I_{i j}}{\sum_{i} I_{i j}} z_{i}$, where $z_{i}$ is the skill intensity of intermediate industry $i$. The weights $\frac{I_{i j}}{\Sigma_{i} I_{i j}}$ indicate industry's $i$ input contribution to produce one unit of product in industry $j$ and are obtained multiplying the input shares of each industry $i$ by the share of total output of the same industry $i$ that goes to salaries i.e. the weights measure the salary-weighted contributions of workers in each industry $i$ to output of industry $j .^{8}$

Taking into account intermediate inputs increases the skill intensity of the lowskill-intensive items and reduces the skill intensity of the high-skill-intensive items. This happens because the low-skill-intensive intermediate inputs, in particular the retail sector (which is an intermediate input in I-O tables), reduce the skill intensity of all final products; however for the low-skill-intensive final products the effect of the retail sector is offset by the contribution of other intermediate inputs which are relatively more skill intensive such as the contribution of the public sector. The estimated correlation coefficient between the raw measure and the adjusted measure is 0.88 .

\section{B. Data for the UK}

The UK sample is drawn from FES data 1994-1997 and includes 26,189 households and their expenditure on 42 non-durable consumption items (see the online Appendix for sample selection, Table A6 for descriptive statistics and Table A7 for the match to LFS data). There is a large difference between the US and the UK data in the percentage of heads of household with some college education: $52 \%$ in the US sample (CEX 1994-1997) and $21 \%$ in the UK sample (some college in the UK is defined as those who left full time education after their 18th year of age). By the same token, skill intensity of the producing industries in the UK is much lower than in the US when measured as the share of workers with a degree level education or more ( $20 \%$ of the total). Therefore in order to establish a better comparison with the US, I consider for the UK also skill intensity calculated as the share of workers with more than high school (48\% of the total). Both skill intensities are calculated on LFS 1994-1997 data (not earlier because of industry codes' consistency) and are adjusted for the use of intermediate inputs with weights that reflect the salary-weighted contribution of workers of other industries (see Table A8 in the online Appendix).

\footnotetext{
${ }^{8}$ As an illustration of the construction of weights I offer the following example that I owe to an anonymous referee. Suppose that two industries have the following expenditure structure: Industry A: $40 \%$ salaries, $20 \%$ interest on capital, $20 \%$ purchases of inputs from industry B, $20 \%$ purchases of inputs from industry A (within sector trading); Industry B: $60 \%$ salaries, $20 \%$ capital, $10 \%$ imports from abroad, $10 \%$ purchases of inputs from industry A. When a consumer spends $\$ 100$ on goods of industry A, that industry will pay salaries of $\$ 40$ to its employees. It will also make purchases from industries B and A which lead to salaries of $\$ 12=(100 * 0.2 * 0.6)$ and $\$ 8=(100 * 0.2 * 0.4)$. Ignoring further iterations of the input-output relationships, the salary-weighted contributions of workers in A and B to output of industry A would be $80 \%=(\$ 48 / \$ 60)$ and $20 \%=(\$ 12 / \$ 60)$, respectively.
} 


\section{Econometric Specification}

The empirical strategy is in two steps: first I estimate education and income elasticities, then I regress the estimates on the corresponding industry's skill intensity. I estimate a system of 38 equations; for each item the specification is:

$$
\omega_{i j}=a_{j}+b_{j} \mathbf{X}_{i}^{\prime}+\gamma_{j} e d_{i}+\varepsilon_{i j} \quad \text { for } j=1, . ., 38 .
$$

$\omega_{i j}=\frac{p_{j} y_{i j}}{x_{i}}$ is the expenditure share of item $j$ by household $i, \mathbf{X}_{i}$ contains the age and sex of the head of household and the number of children under 18 in the household, $e d_{i}$ is an education dummy which is equal to one if the head of household has some college education. The 38 equations are stacked in a fixed effect regression with constraints. To be consistent with a demand system $\left(\sum_{j} \omega_{i j}=1\right)$, the following restrictions are imposed: $\sum_{j} a_{j}=1, \sum_{j} b_{j}=0$ for each $b_{j}, \sum_{j} \gamma_{j}=0$. Standard errors are clustered at the household level. I do not include prices because 38 prices are collinear. ${ }^{9}$

Although the focus of the model of Section I is mainly on education elasticities, I also estimate income elasticities because they work as a complementary mechanism which may also favor skill-intensive products so that rising income will reinforce the education demand effect. In a second specification of System 4, instead of the term in the head's education level, I introduce a term in log expenditure where $\delta_{j} \log x_{i}$ is the log of real (deflated by CPI index) total expenditure of household $i$ with restrictions $\sum_{j} \delta_{j}=0$. Income elasticities are a more popular concept in empirical work and, while education elasticities reflect the consumption response to permanent income changes, income elasticities reflect the response to current income.

The education elasticities are equal to $\widehat{\eta}_{j}^{e d}=\frac{\widehat{\gamma}_{j} * \overline{e d}}{\bar{\omega}_{j}}$ where $\bar{\omega}_{j}$ is the average budget share of item $j$ and $\overline{e d}$ is the percentage of heads of household who have some college education ( $52 \%$ in US data); weighted by the average share in the budget, they average to zero across the 38 expenditure items. The budget elasticities are equal to $\widehat{\eta}_{j}^{\text {budget }}=\frac{\widehat{\delta}_{j}}{\bar{\omega}_{j}}+1$ and their weighted average is equal to one. ${ }^{10}$

\footnotetext{
${ }^{9}$ In Section IV where I bring the theoretical model to the data I aggregate the 38 items in two aggregate groups (high-skill and low-skill-intensive). At that point I include also a relative price index constructed as the aggregation of the single items' prices and I estimate the price elasticities needed to parametrize the model.

${ }^{10}$ Income elasticities refer to quantities while I have expenditure shares i.e. budget elasticities. For convenience in the text and in the tables I often call them income elasticities. The theory model implies two distinct income elasticities, one by each education group, however I estimate one common income elasticity because the coefficient estimates are rarely different across education group.
} 
Table 1 - Estimates of Education and Income Elasticities.

\begin{tabular}{|c|c|c|c|c|c|}
\hline & $\begin{array}{l}\text { Education } \\
\text { Coefficient }\end{array}$ & $\begin{array}{l}\text { Education } \\
\text { Elasticity }\end{array}$ & $\begin{array}{c}\text { Income } \\
\text { Coefficient }\end{array}$ & $\begin{array}{c}\text { Income } \\
\text { Elasticity }\end{array}$ & $\begin{array}{c}\text { Skill } \\
\text { Intensity }\end{array}$ \\
\hline Domestic Services & 0.008 & 0.185 & 0.005 & 1.238 & 0.131 \\
\hline Clothing and Shoes & 0.007 & 0.074 & 0.006 & 1.116 & 0.136 \\
\hline Household Supplies & 0.006 & 0.100 & 0.011 & 1.321 & 0.163 \\
\hline Food Off-Premise & -0.052 & -0.147 & -0.047 & 0.740 & 0.236 \\
\hline Clothing Services & 0.000 & 0.024 & -0.001 & 0.907 & 0.240 \\
\hline Repairs, Greasing, Parking etc. & 0.012 & 0.211 & 0.012 & 1.380 & 0.240 \\
\hline Jewelry and Watches & 0.002 & 0.208 & 0.003 & 1.658 & 0.242 \\
\hline Tobacco Products & -0.012 & -0.415 & -0.004 & 0.716 & 0.255 \\
\hline Alcohol On-Premise & 0.002 & 0.149 & 0.001 & 1.140 & 0.265 \\
\hline Food On-Premise & 0.013 & 0.121 & 0.005 & 1.092 & 0.266 \\
\hline Barbershops, Beauty Parlors etc. & 0.001 & 0.041 & 0.000 & 0.973 & 0.273 \\
\hline Taxicab, Railway, Bus and Travel & 0.001 & 0.272 & 0.002 & 1.542 & 0.275 \\
\hline Mass Transit Systems & -0.001 & -0.073 & 0.000 & 0.914 & 0.277 \\
\hline Magazines, Newspapers, Toys etc. & 0.007 & 0.182 & -0.001 & 0.942 & 0.282 \\
\hline Housing & -0.025 & -0.099 & -0.028 & 0.787 & 0.282 \\
\hline Tires, Tubes, Accessories and Parts & 0.000 & -0.018 & 0.001 & 1.142 & 0.297 \\
\hline Alcohol Off-Premise & 0.000 & 0.002 & 0.000 & 0.949 & 0.339 \\
\hline Water and Other Sanitary Services & -0.001 & -0.040 & -0.001 & 0.962 & 0.346 \\
\hline Ophthalmic Products & 0.001 & 0.152 & 0.001 & 1.245 & 0.355 \\
\hline Gas & -0.003 & -0.109 & -0.002 & 0.878 & 0.378 \\
\hline Gasoline and Oil & -0.007 & -0.070 & -0.005 & 0.903 & 0.381 \\
\hline Recreation and Sports Equipment & 0.009 & 0.184 & 0.010 & 1.398 & 0.410 \\
\hline Electricity & -0.012 & -0.141 & -0.006 & 0.868 & 0.422 \\
\hline Other Recreation Services & 0.013 & 0.176 & 0.010 & 1.242 & 0.441 \\
\hline Telephone and Telegraph & -0.003 & -0.040 & -0.005 & 0.866 & 0.458 \\
\hline Drug Preparations & -0.004 & -0.190 & -0.001 & 0.938 & 0.467 \\
\hline Fuel Oil and Coal & -0.002 & -0.225 & 0.000 & 0.910 & 0.473 \\
\hline Health Insurance & -0.004 & -0.056 & -0.004 & 0.910 & 0.532 \\
\hline Expense of Handling Life Insurance & 0.002 & 0.090 & 0.005 & 1.371 & 0.539 \\
\hline Auto Insurance & 0.002 & 0.032 & 0.005 & 1.163 & 0.539 \\
\hline Hospitals & 0.000 & -0.005 & 0.002 & 1.446 & 0.543 \\
\hline Airline Fares & 0.007 & 0.421 & 0.005 & 1.625 & 0.550 \\
\hline Religious and Welfare Activities & 0.007 & 0.216 & 0.000 & 1.024 & 0.590 \\
\hline Business Services & 0.002 & 0.054 & 0.006 & 1.439 & 0.620 \\
\hline Physicians, Dentists, Medical Prof. & 0.004 & 0.134 & 0.006 & 1.363 & 0.671 \\
\hline Other Education Services & 0.005 & 0.324 & 0.005 & 1.606 & 0.699 \\
\hline Nursery, Elem. and Sec. Education & 0.002 & 0.435 & 0.001 & 1.422 & 0.719 \\
\hline Higher Education & 0.012 & 0.495 & 0.005 & 1.426 & 0.800 \\
\hline
\end{tabular}




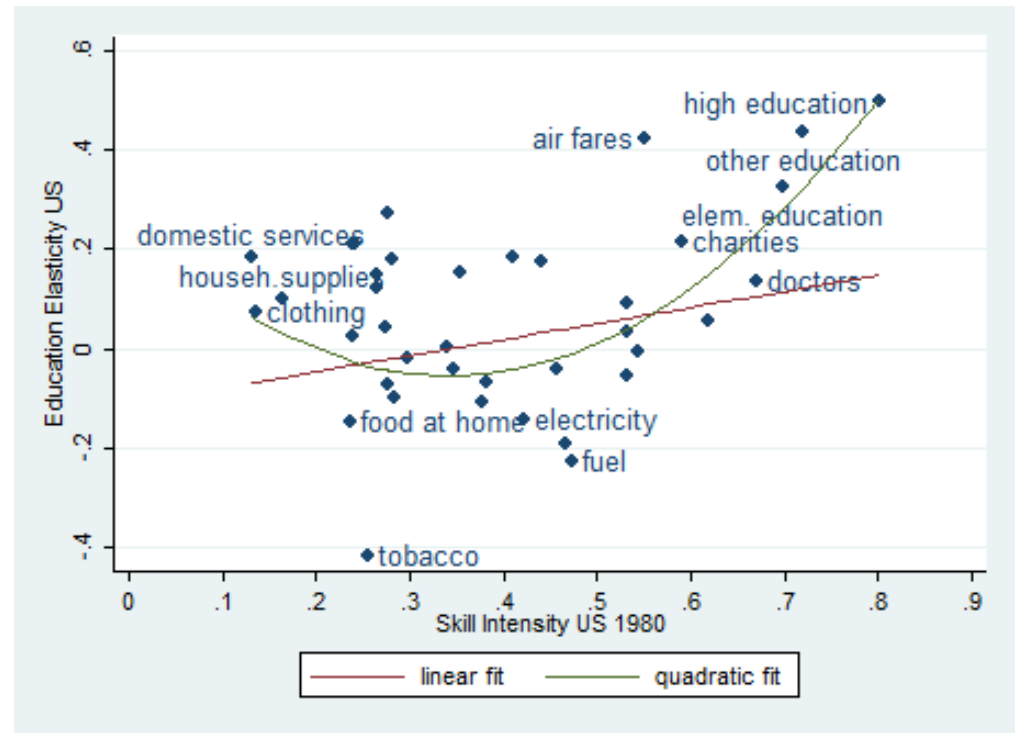

Figure 1. Elasticities AND SkILl intensities US

Note: Fitted values are predicted by a weighted OLS regression of education elasticities on industry skill intensity measured in 1980 and its square. Weights are the mean shares of the consumption items in total expenditure. Elasticities are estimated on pooled CEX 1994-1997 data, skill intensity on CPS 1979-1980 data.

\section{Regression Results of Elasticities and Skill Intensities}

Table 1 shows the estimated coefficients on the education dummy and on total expenditure for each one of the 38 items estimated on the CEX pooled sample of years 1994-1997. The coefficients on education and total expenditure are obtained with two separate systems. For ease of interpretation, the items are ranked in ascending order according to the skill intensity of their producing industries which is shown in the last column of Table 1. The Table also shows the education and income elasticities. Poorly educated head of households tend to spend relatively more (i.e. low education elasticity) on food consumed at home and utilities; high-educated heads allocate a large proportion of their family budget to low-skillintensive services such as repairs and domestic services and an even larger share to high-skill-intensive services such as medical and business services and expenditure on education of all levels. A similar pattern is evident for income elasticities. The coefficient of correlation between income and education elasticities is 0.78 thus indicating that the effect of current and permanent income on consumption is similar.

Figure 1 plots education elasticities against skill intensity (calculated in 19791980), together with a linear and a quadratic fit obtained by a OLS regression weighted by the mean expenditure share of each consumption item (a measure 
of the importance of the item in the household budget). The coefficient on the linear weighted regression is $0.32(0.17)$. When the same education elasticities are plotted against skill intensity adjusted for intermediate inputs, the results do not change much and the linear coefficient becomes 0.47 (0.27). The significant coefficients of the linear regressions of Table 2 indicate that educated individuals tend to consume on average more high-skill-intensive goods and services. The magnitude of the coefficient, however, is not very informative because it is expressed in elasticities units and one needs a model to quantify how much an increase in the skill ratio is translated into an increase in the skill premium (see Section IV).

While the model implies a positive relationship between elasticities and skill intensities, Figure 1 suggests a more nuanced pattern of "polarization of consumption"towards consumption items at the two extremes of the skill intensity distribution. For this reason I estimate a quadratic relationship as well as a linear one. Although the elasticities tend to be higher for both low-skill-intensive and high-skill-intensive consumption items, the overall demand shift is mainly in favor of skill-intensive products and services and the shape of the relationship is a $\mathrm{J}$ shape rather than a $U$ shape.

Table 2 reports the results of the linear (and quadratic) regression:

$$
\widehat{\eta}_{j}=\alpha+\beta z_{j}+\varepsilon_{j}
$$

where $\widehat{\eta}_{j}$ is in turn the education and the income elasticity for commodity $j$ and $z_{j}$ is skill intensity of industry $j$. All regressions are weighted by the mean share of the consumption item in total expenditure (regressions weighted by the inverse of the estimated variance yield very similar results).

In Panel A of Table 2, education and income elasticities are regressed on the skill intensity $z_{j}$ of the manufacturing industry in 1979-1980. The table shows that the positive relationship of skill intensities with income elasticities is even stronger than the one with education elasticities: the coefficient on the linear regression is $0.58(0.26)$ and $0.82(0.42)$ for income elasticities. The coefficients of the quadratic regressions show that the J-shaped relationship holds for both education and income elasticities. Panel B confirms the results of Panel A using the adjusted skill intensity measure which accounts for the contribution of intermediate inputs. Table A9 in the online Appendix shows some robustness checks excluding expenditure on education from the regression or separating tradable goods and nontradable services. ${ }^{11}$

\footnotetext{
${ }^{11}$ If I exclude the expenditure item regarding education from the regression, the linear regression loses significance but the quadratic relationship remains significant. Separating nontradables and tradables, the results indicate significant coefficients on the linear and quadratic terms for nontradables and insignificant coefficient for tradables. This is consistent with the fact that the hypothesis advanced in this paper applies mostly to nontraded services whose domestic demand is what matters while the demand of American traded goods is a function also of the tastes of consumers all over the world. Finally the table shows that the positive J-shaped relationship holds also with coefficients rather than elasticities and therefore is not due to the transformation of the coefficients into elasticities.
} 
Table 2-OLS Regression of Estimated Education and Income Elasticities on Two Measures OF SKILL INTENSITY

\begin{tabular}{|c|c|c|c|c|}
\hline \multirow[t]{2}{*}{ Dependent variable } & \multicolumn{2}{|c|}{ Education Elasticity } & \multicolumn{2}{|c|}{ Income Elasticity } \\
\hline & Panel A & & & \\
\hline Skill intensity 1980 & $\begin{array}{c}0.322^{*} \\
(0.170)\end{array}$ & $\begin{array}{c}-1.806^{* *} \\
(0.707)\end{array}$ & $\begin{array}{c}0.581^{* *} \\
(0.264)\end{array}$ & $\begin{array}{c}-2.325^{* *} \\
(1.129)\end{array}$ \\
\hline Skill intensity 1980 squared & & $\begin{array}{c}2.641^{* * *} * \\
(0.856)\end{array}$ & & $\begin{array}{c}3.607^{* *} \\
(1.368)\end{array}$ \\
\hline Constant & $\begin{array}{c}-0.110^{*} \\
(0.0630)\end{array}$ & $\begin{array}{c}0.254^{*} \\
(0.131)\end{array}$ & $\begin{array}{c}0.802^{* * *} \\
(0.0977)\end{array}$ & $\begin{array}{c}1.299^{* * *} * \\
(0.209)\end{array}$ \\
\hline R-squared & 0.091 & 0.285 & 0.119 & 0.265 \\
\hline & Panel B & & & \\
\hline Adjusted skill intensity & $\begin{array}{c}0.468^{*} \\
(0.269)\end{array}$ & $\begin{array}{c}-4.532^{* * *} \\
(1.575)\end{array}$ & $\begin{array}{c}0.824^{*} \\
(0.419)\end{array}$ & $\begin{array}{c}-5.900^{* *} \\
(2.547)\end{array}$ \\
\hline Adjusted skill intensity squared & & $\begin{array}{c}5.865^{* * *} * \\
(1.825)\end{array}$ & & $\begin{array}{c}7.887^{* *} \\
(2.953)\end{array}$ \\
\hline Constant & $\begin{array}{c}-0.178^{*} \\
(0.105)\end{array}$ & $\begin{array}{c}0.826^{* *} \\
(0.326)\end{array}$ & $\begin{array}{c}0.688^{* * *} \\
(0.163)\end{array}$ & $\begin{array}{c}2.037^{* * *} \\
(0.527)\end{array}$ \\
\hline R-squared & 0.078 & 0.288 & 0.097 & 0.250 \\
\hline
\end{tabular}




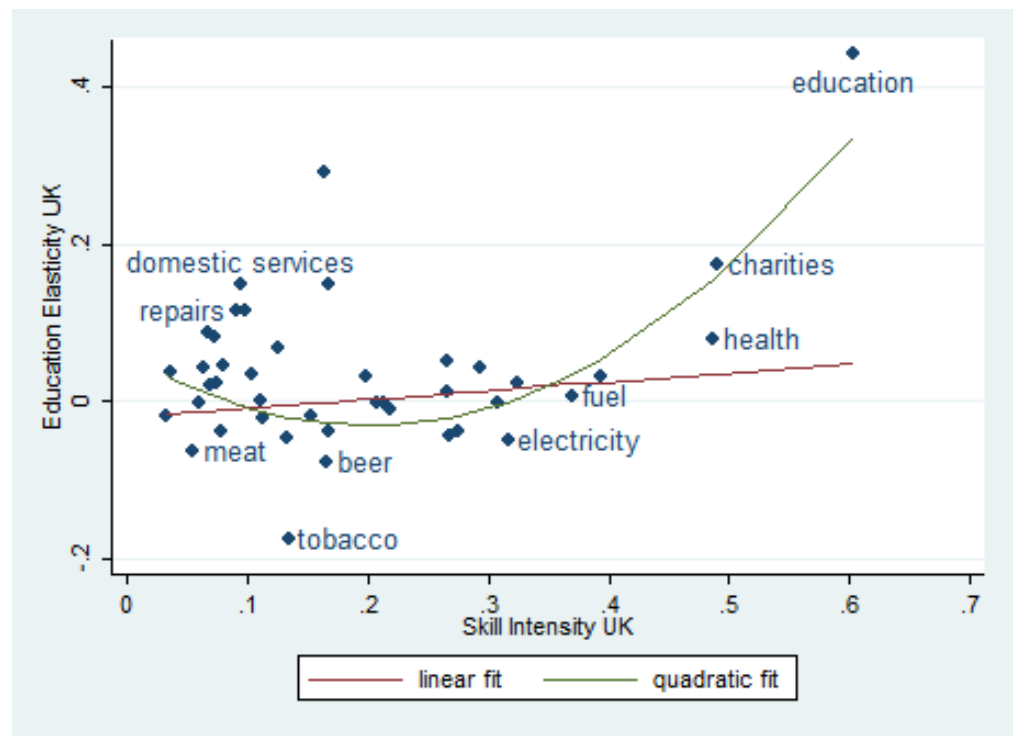

Figure 2. Elasticities AND SKILL INTEnsities UK

Note: Fitted values are predicted by an OLS regression of education elasticities on industry skill intensity and its square. Skill intensity is measured as the proportion of workers with some college on LFS 19941997 data, education elasticities are estimated on pooled FES 1994-1997 data.

\section{E. Regression Results for the UK}

The results on UK data are presented in Figure 2 which is the equivalent of Figure 1 for the US (except that skill intensity is calculated in 1994-97 instead of 1979-80). The coefficient of the weighted linear regression is 0.11 (0.09). Also in the UK the relationship between elasticities and skill intensities has a polarized shape and the results regarding income elasticities (not shown) resemble those for education elasticities.

Since skill intensity in all sectors is much lower in the UK than in the US, in order to improve the comparison with the US I also use a definition of skill based on high-school diploma in the UK. When this measure of skill intensity is used, the coefficient of the linear regression of education elasticities (the education dummy in the system of equation indicates heads of households with high school or more) on skill intensities becomes 0.45 (0.20) (see Table A10 and A11 in the online Appendix for the UK results).

The validity of the positive J-shaped relationship also for the UK lends credence to the consumption elasticity mechanism. The relationship holds notwithstanding the differences between the US and the UK in the share of educated workers and in the size of the public sector for education and health which affects the incidence 
of out of pocket expenditures on those services. ${ }^{12}$ It is reassuring that the positive relationship between elasticities and skill intensities holds in two countries with public sectors of different size.

\section{F. Interpretation and Extension of the Results}

In this section I discuss whether elasticity estimates may reflect composition effects or time trends, rather than a true "education effect".

FAMiLy TYPE. - One may wonder whether the J-shaped relationship is driven by composition effects, for example different family types. In the recent literature on polarization the increase in consumption of low-skill-intensive services is attributed to the increasing education of women: more educated women have a higher opportunity cost of time and buy low-skill-intensive services on the market (Black and Spitz-Oener 2009; Cortes and Tessada 2011; Mazzolari and Ragusa 2013). Panel A of Table 3 shows that the significant relationship between elasticities and skill intensities is not driven by families where the spouse is college educated. I find that there are no major differences across family types (single heads, families with college- and non-college-educated spouses). The correlation between education elasticities estimated on the sample of singles and of families with low-educated (high-educated) spouses is 0.88 (0.77), while the correlation between education elasticities of families with low- and high-skilled spouses is 0.72. This suggests that the explanation based on product demand elasticities is likely to work independently of the explanation based on an increase in consumption of market-provided services because of an increase in the opportunity cost of time for women.

Time TREnds. - One further concern is that the pattern of education elasticities may capture some time trends. For example Autor and Dorn (2013) show that wage polarization appeared in the 1990s but it is not in the data in the 1980s. One could argue that, if product demand elasticities contribute to polarization, then the quadratic relationship between elasticities and skill intensities may follow the same timing.

In Panel B of Table 3 I divide the data in three periods (1984-1989, 1990-1996 and 1997-2002) to verify whether the estimates of elasticities (or their relationship with skill intensity) change over time. ${ }^{13}$ The coefficients of a linear regression of

\footnotetext{
${ }^{12}$ Consumption surveys (both FES and CEX) collect information only about private consumption however much of total consumption is public government consumption which may also plausibly react to changes in the education composition of the electorate. This may reinforce or partially offset the mechanism based on private consumption highlighted here.

${ }^{13}$ The micro data of the Consumer Expenditure Survey are available from 1984 to 2012 but the NBER dataset with a consistent aggregation of expenditures stops in 2002. Since the purpose of this paper is to assess the effect of consumption elasticities on the increase of the college premium, the most relevant decades are the 1980s and the 1990s, while in the year 2000s the increase in inequality slowed down (Autor, Katz, and Kearney 2006 and 2008).
} 
Table 3-Education Elasticities: Family Composition and Time Effects

\begin{tabular}{|c|c|c|c|c|c|c|}
\hline \multirow{4}{*}{$\begin{array}{l}\text { Adj. skill intensity } \\
\text { Adj. skill intensity squared }\end{array}$} & \multicolumn{6}{|c|}{ Panel A: Elasticities by Family Type } \\
\hline & \multicolumn{2}{|c|}{ Singles } & \multicolumn{2}{|c|}{ Spouse less than college } & \multicolumn{2}{|c|}{ Spouse some college } \\
\hline & $\begin{array}{c}0.537^{* *} \\
(0.264)\end{array}$ & $\begin{array}{c}-4.052^{* *} \\
(1.576)\end{array}$ & $\begin{array}{c}0.201 \\
(0.215)\end{array}$ & $\begin{array}{c}-3.584^{* * *} \\
(1.278)\end{array}$ & $\begin{array}{c}0.059 \\
(0.172)\end{array}$ & $\begin{array}{c}-2.629^{* *} \\
(1.037)\end{array}$ \\
\hline & & $\begin{array}{c}5.374^{* * *} \\
(1.824)\end{array}$ & & $\begin{array}{c}4.432^{* * *} \\
(1.480)\end{array}$ & & $\begin{array}{c}3.106^{* *} \\
(1.184)\end{array}$ \\
\hline Constant & $\begin{array}{c}-0.201 * \\
(0.102)\end{array}$ & $\begin{array}{c}0.721^{* *} \\
(0.326)\end{array}$ & $\begin{array}{l}-0.075 \\
(0.082)\end{array}$ & $\begin{array}{c}0.685^{* *} \\
(0.265)\end{array}$ & $\begin{array}{l}-0.023 \\
(0.068)\end{array}$ & $\begin{array}{c}0.521^{* *} \\
(0.217)\end{array}$ \\
\hline \multirow[t]{3}{*}{ R-squared } & 0.103 & 0.282 & 0.024 & 0.225 & 0.003 & 0.167 \\
\hline & \multicolumn{6}{|c|}{ Panel B: Elasticities Estimated Over Time } \\
\hline & \multicolumn{2}{|c|}{ Years 1984-1989 } & \multicolumn{2}{|c|}{ Years 1990-1995 } & \multicolumn{2}{|c|}{ Years 1996-2002 } \\
\hline Adj. skill intensity squared & $\begin{array}{c}0.396 \\
(0.263)\end{array}$ & $\begin{array}{l}-5.028^{* * *} \\
(1.477) \\
6.416^{* * *} \\
(1.727)\end{array}$ & $\begin{array}{l}0.488^{*} \\
(0.269)\end{array}$ & $\begin{array}{c}-4.797^{* * *} \\
(1.555) \\
6.221^{* * *} \\
(1.809)\end{array}$ & $\begin{array}{c}0.555^{* *} \\
(0.261)\end{array}$ & $\begin{array}{c}-4.466^{* * * *} \\
(1.535) \\
5.853^{* * *} \\
(1.769)\end{array}$ \\
\hline Constant & $\begin{array}{l}-0.149 \\
(0.102)\end{array}$ & $\begin{array}{c}0.929 * * * \\
(0.303)\end{array}$ & $\begin{array}{c}-0.185^{*} \\
(0.105)\end{array}$ & $\begin{array}{c}0.872^{* *} \\
(0.321)\end{array}$ & $\begin{array}{c}-0.212^{* *} \\
(0.103)\end{array}$ & $\begin{array}{c}0.802^{* *} \\
(0.319)\end{array}$ \\
\hline R-squared & 0.059 & 0.325 & 0.084 & 0.315 & 0.111 & 0.323 \\
\hline
\end{tabular}

Note: $\mathrm{N}=38$. Each column is the result of a OLS regression of education elasticities on skill intensity weighted by the mean budget share of the consumption item. Skill intensity is always adjusted for intermediate inputs. *** Significant at the 1 percent level. ** Significant at the 5 percent level. * Significant at the 10 percent level. 
education elasticities on input-adjusted skill intensity are $0.396(0.263), 0.488$ (0.269) and $0.555(0.261)$ in the three periods. The pairwise correlation between education elasticities of the three periods is very high, between 0.98 and 0.99 (the same for income elasticities). The high correlation suggests that the mechanism based on elasticities is stable over time and does not simply capture some time trend.

If consumption preferences are stable over time, then an increase in skill supply should correspond to a proportional increase in consumption of skill-intensive goods and services. While in this paper I focus on cross-sectional evidence of the relationship between elasticities and skill intensities, time series evidence already cited in the Introduction seems to be consistent with this implication. Table A1 in the online Appendix reports the expenditure shares of the main consumption aggregates in each decade from 1972 through 2012. In the decades from 1984 to 2012 the skill supply (the share of heads of households with more than 12 years of education) grew approximately by $1 \%$ per year or less and the expenditure share of skill-intensive services (the sum of health, education and personal insurance) went up approximately by $1 \%$ a decade while the share of food, tobacco and apparel combined (two low-skill-intensive products) went down by $1 \%$ a decade. ${ }^{14}$

\section{Evidence on Industry Employment Shares within MSAs}

In this section I test the second implication of the model of Section I using variation within cities (MSAs). The model predicts that the increase in the relative number of skilled workers will increase employment shares of skill-intensive industries and decrease that of low-skill-intensive industries. On top of this supply effect there will be a positive demand effect on industry employment shares that will be larger the larger is the education elasticity of consumption. ${ }^{15}$

This prediction can be tested on industry data at the MSA level with two provisions. Firstly we have to focus only on nontradables: the predicted effect of education elasticities on industry employment shares is expected to be detectable within cities if we assume that services cannot be traded outside of a local labor market. On the contrary there should be no effect for tradables at the local level: the market for tradables is national, and much of the additional local demand

\footnotetext{
${ }^{14}$ Under the assumption that consumption preferences do not change over time, a rapid growth of skill supply should imply a more rapid shift in product demand. During the 1970s, the supply of skilled workers was increasing much faster than in later periods thanks to a vast expansion in the number and size of public institutions of higher education (Katz and Goldin 2008). In Table A1 the share of educated heads of household rose from $27.5 \%$ in 1972 to $43 \%$ in 1984 while the expenditure share of food and apparel fell by $3 \%$ and the share of skill-intensive services (health, education and personal insurance) went up only by $0.4 \%$. Unfortunately there are no micro data before 1984 therefore we cannot say if education elasticities were the same in the 1970s as in later periods. Apparently in that period most expenditure shifted to housing and transportation and only partially to skill-intensive services.

${ }^{15}$ Although the model has equivalent predictions for industry wage bill shares $\frac{w_{h} H_{1}+w_{l} L_{1}}{H+L}$, the analysis at the MSA level is limited to employment shares because the analysis of industry wage bill shares faces an additional problem: unless skilled workers earn the same college premium across all industries, the wage bill share will reflect also the different premia across industries and not necessarily reflect increased consumption demand.
} 
is likely to benefit other cities. For this reason I will use the tradable sectors as control group in a specification check.

Secondly, to break down the model at the MSA level we need some assumptions relative to cross-city labor mobility and wage adjustment. I follow the framework recently proposed in the literature on local multipliers (Moretti, 2010). I assume the existence of an upward-sloping local labor supply which depends on the degree of labor mobility across MSAs and I assume further that within a MSA labor is mobile across sectors so that marginal product and wages of each skill group are equalized across sectors.

In consequence of a positive demand shock to the skill ratio $H / L$ in tradable industry $j$ in MSA $m$ (due for example to an exogenous nationwide increase in skill intensity combined with the particularly favorable industrial composition of MSA $m$ ), employment share of industry $j$ will increase but the shock may also affect local employment in other industries (i.e. the local multiplier effect). In fact the shock will increase the relative wage of skilled workers in the city and will attract existing residents and new immigrants, depending on the degree of labor mobility across MSAs. On top of this supply effect, which increases employment shares of skill-intensive industries, there will be a positive demand effect on all nontradable local industries that will be larger the larger is the education elasticity of demand. ${ }^{16}$

In the following I estimate the effect of an increase of $H / L$ in tradable industries on the employment share of nontradable industries allowing for labor mobility and wage adjustment at the MSA level. I use the skill ratio in tradables only because it is less polluted by reverse causality (there is a mechanical relationship between the skill ratio in a MSA and employment in skill-intensive sectors in the same city). Before introducing the estimation strategy I will briefly describe the data.

\section{A. Census Data at the MSA Level}

I use the 5\% sample of decennial census in 1980, 1990 and 2000 Integrated Public Use Microsample Series (IPUMS) files, the only data which have sufficient sample size for MSA-level analysis (see the online Appendix for sample selection details and Tables A12 and A13 for descriptive statistics). After selecting a balanced sample of MSAs which are present in all decades and keeping only MSAindustry cells with more than 200 workers in 1980, the final dataset contains 4,130 observations on $163 \mathrm{MSAs}$ each of which with a different number of industries (the observation of nontradables industries are 3,186, the rest are tradables). The observations are MSA-industry-year weighted averages (using IPUMs personal weights) and, since the regressions are in changes, the final sample includes two observations per each MSA and each industry, corresponding to the periods 19801990 and 1990-2000.

\footnotetext{
${ }^{16}$ The general equilibrium effect on wages and prices may partially undo the effect of the increase in demand for local services making labor costs higher and reducing their supply, however, if local labor supply is very elastic, labor costs will not increase much and the offsetting effect will be small.
} 
Because the model predicts different effects in skill-intensive sectors (where both supply and demand effects are positive) and in low-skill-intensive sectors (where the supply effect is negative), the sample is divided in high-skill and low-skill nontradables (see Table A12 in the online Appendix). A simple regression of changes in employment shares on changes in the (log) skill ratio within MSA yields a positive significant coefficient for high-skill-intensive industries, a negative significant coefficient for low-skill-intensive industries and a insignificant coefficient for tradables. ${ }^{17}$ These results are consistent with the evidence of the previous section and indicate that employment shares of skill-intensive services rise more in cities where there is more skill upgrading but they do not account explicitly for the consumption elasticity channel.

\section{B. The Empirical Strategy}

To account for elasticities I estimate the following equation where, for ease of interpretation of the interaction coefficient, the sectors are grouped with a high/low education elasticity dummy $\left(h i g h_{j}\right.$ indicates an industry $j$ with education elasticity higher than the median):

(6) $\begin{aligned} \Delta E m p_{-} S h a r e_{j m t}^{N T R}=\alpha+\beta_{0}\left(\Delta \frac{H}{L}_{m t}^{T R}\right)+ & \beta_{1} h i g h_{j}+\beta_{2}\left(\Delta \frac{H}{L}_{m t}^{T R} \times h i g h_{j}\right) \\ & +\delta_{j}+\gamma_{m}+\eta_{1990-2000}+\varepsilon_{j m t} .\end{aligned}$

$\Delta E m p_{-} S h a r e_{j m t}^{N T R}$ is the decadal change in the share of the MSAs' $m$ workforce employed in nontradable (NTR) industry $j$ between 1980 and 1990 and between 1990 and 2000 (indicated by $t$ ). $\Delta \frac{H}{L}_{m t}^{T R}$ is the decadal change in the log of the skill ratio in tradable (TR) industries in MSA $m$ : to avoid the potential reverse causality, $\Delta \frac{H}{L}_{m t}^{T R}$ is measured using changes in the skill ratio only in the tradable sector. The coefficient of interest is $\beta_{2}$ which captures the differential effect on the employment share of nontradable sectors with high education elasticity. All regressions include MSA and industry fixed effects and one time (decade) dummy to control for common local, industry and temporal shocks and are weighted by the average employment of the industry $j$ of city $m$ in $1980 .{ }^{18}$ Standard errors are clustered at the MSA level.

\footnotetext{
${ }^{17}$ The coefficients on the log skill ratio in regressions which include decade, MSA and industry dummies are $0.020(0.004),-0.035(0.017)$ and $0.027(0.037)$ respectively. The cross-MSA average employment share of a high-skill (low-skill) intensive industry in 1980 is 7\% (6\%), of a tradable industry is 5.3\% (Table A13 of descriptive statistics in the online Appendix).

${ }^{18}$ Time-invariant differences across MSAs are controlled for by MSA dummies but the coefficients might be biased by city-specific time-variant shocks that are correlated with both changes in the MSA's skill ratio and changes in industry employment shares. To test the robustness of these results I include in the regressions the MSA-level changes in sex ratios, in average age and in the share of immigrants to control for other concurrent secular changes in labor supply that may affect the growth of some industries, mainly low-skill-intensive sectors which are also intensive in female and immigrant labor. Results are qualitatively unchanged and are available upon request.
} 
Table 4-Changes in Nontradable and Tradable Industries' Employment Shares at the MSA LEVEL

\begin{tabular}{|c|c|c|c|c|c|c|}
\hline & \multicolumn{2}{|c|}{$\begin{array}{l}\text { High-Skill } \\
\text { Nontradables }\end{array}$} & \multicolumn{2}{|c|}{$\begin{array}{c}\text { Low-Skill } \\
\text { Nontradables }\end{array}$} & \multicolumn{2}{|c|}{ Tradables (TR1) } \\
\hline & $(1)$ & $(2)$ & $(3)$ & (4) & $(5)$ & (6) \\
\hline & OLS & IV & OLS & IV & OLS & IV \\
\hline$\Delta \log \left(\frac{H}{L}_{m t}^{T R}\right)$ & $\begin{array}{l}-0.002 \\
(0.002)\end{array}$ & $\begin{array}{l}-0.007 \\
(0.036)\end{array}$ & $\begin{array}{l}0.023^{*} \\
(0.013)\end{array}$ & $\begin{array}{l}-0.225 \\
(0.688)\end{array}$ & & \\
\hline High elasticity & $\begin{array}{c}0.003 \\
(0.002)\end{array}$ & $\begin{array}{c}-0.012^{* * * *} \\
(0.003)\end{array}$ & $\begin{array}{c}0.011^{* * *} \\
(0.003)\end{array}$ & $\begin{array}{l}0.025^{*} \\
(0.013)\end{array}$ & $\begin{array}{c}0.009 \\
(0.014)\end{array}$ & $\begin{array}{c}0.060 \\
(0.059)\end{array}$ \\
\hline$\Delta \log \left(\frac{H}{L}_{m t}^{T R}\right)^{*}$ High elast & $\begin{array}{c}0.009 * * * \\
(0.002)\end{array}$ & $\begin{array}{c}0.045^{* * *} \\
(0.012)\end{array}$ & $\begin{array}{c}-0.026^{* *} \\
(0.010)\end{array}$ & $\begin{array}{l}-0.050 \\
(0.036)\end{array}$ & & \\
\hline$\Delta \log \left(\frac{H}{L}_{m t}^{T R 0}\right)$ & & & & & $\begin{array}{l}-0.006 \\
(0.025)\end{array}$ & $\begin{array}{l}-0.096 \\
(0.170)\end{array}$ \\
\hline$\Delta \log \left(\frac{H}{L}_{m t}^{T R 0}\right) *$ High elast & & & & & $\begin{array}{l}-0.032 \\
(0.039)\end{array}$ & $\begin{array}{c}0.255 \\
(0.174)\end{array}$ \\
\hline Observations & 1,530 & 1,530 & 794 & 794 & 159 & 159 \\
\hline R-squared & 0.256 & & 0.280 & & 0.392 & \\
\hline $\mathrm{P}>\mathrm{F}$ Excl Instrument1 & & 0.685 & & 0.893 & & 0.697 \\
\hline $\mathrm{P}>\mathrm{F}$ Excl Instrument2 & & $6.03 \mathrm{e}-10$ & & $2.74 \mathrm{e}-08$ & & 0.0327 \\
\hline
\end{tabular}

Note: In the first four columns the dependent variable is the decadal (1980-1990 and 1990-2000) change in nontradable (NTR) industry employment shares; the independent variable is the decadal change in the log skill ratio in tradable (TR) industries. In the last two columns changes in employment shares in tradables group TR1 are regressed on changes in the log skill ratios in tradables group TR0. Lowskill/high-skill nontradables and tradables (group TR0 and TR1) are defined in Table A12 in the online Appendix. The instruments are a weighted sum of tradable industry decadal growth of $H / L$ projected on initial MSAs industry structure in 1980. All models contain MSA and industry dummies and one time dummy. The dummy "High elasticity" indicates sectors with education elasticity higher than the median $=0.09$. Only MSA-industry cells with at least 200 employees in 1980 are in the sample. All regressions are weighted by the average employment of industry $i$ in city $m$ in 1980 . Robust standard errors clustered by MSA. *** Significant at the 1 percent level. ** Significant at the 5 percent level. $*$ Significant at the 10 percent level.

To identify exogenous changes in the skill ratio of the tradable sector, I use as an instrument the weighted average of nationwide skill intensity growth in tradable industries, with weights reflecting the city-specific employment share in those sectors in 1980. The instrument is $\widehat{\Delta \frac{H^{T R}}{m t}}=\sum_{j=1}^{n}$ emp_share $_{j m 1980} * \Delta \frac{H}{L}_{j t}^{T R}$, where emp_share $_{j m 1980}$ is the share of industry $j$ in total employment in the tradable sector in MSA $m$ in 1980 and $\Delta \frac{H}{L}_{j t}^{T R}$ is the nationwide change in the skill ratio between 1980 and 1990 and between 1990 and 2000 in tradable industry $j$ : if the skill ratio in a specific tradable industry increases at national level, the MSA where that same industry employs a larger share of the tradable sector experiences a positive shock to skill intensity.

As a specification check, in the last two columns of Table 4 I use the tradable 
sector where there should be no effect. Equation 6 becomes:

$$
\begin{gathered}
\Delta E m p_{-} S h a r e_{j m t}^{T R 1}=\alpha+\beta_{0}\left(\Delta \frac{H}{L}_{m t}^{T R 0}\right)+\beta_{1} h i g h_{j}+ \\
+\beta_{2}\left(\Delta \frac{H}{L}_{m t}^{T R 0} \times h i g h_{j}\right)+\delta_{j}+\gamma_{m}+\eta_{1990-2000}+\varepsilon_{j m t}
\end{gathered}
$$

where $\Delta E m p_{-} S h a r e_{j m t}^{T R 1}$ is the employment share in a randomly selected part of the tradable sector (TR1) and $\Delta \frac{H}{L}_{m t}^{T R 0}$ is the change in the log skill ratio in the rest of the tradable sector (TR0). The instrument is built in an equivalent fashion as described above using TR0 sectors.

The IV estimates establish what happens to industry employment shares in a city when the city experiences an increase in the skill ratio that is driven purely by an increase in the relative demand for college graduates. By contrast, the OLS estimate establishes the same effect when the increase in the skill ratio may be driven by either demand or supply shocks.

\section{Results on Industry Employment Shares at the MSA Level}

Table 4 indicates that an exogenous increase in the skill intensity in the tradable industry results in an increase in local employment in the high-skill-intensive nontradable sector in a city, particularly for those sectors that are educationelastic. The OLS and IV elasticities of the interaction term are 0.009 and 0.045 , respectively (see columns 1 and 2). The latter indicates that a ten percent increase (in a decade) in the skill ratio in the tradable sector in a city is associated with a 0.45 percentage points (over an average employment share of $7 \%$ ) higher increase in the employment share in skill-intensive nontradables with a high education elasticity (like health and education services) with respect to those with low education elasticity.

For low-skill-intensive nontradables the effect is null (column 4, IV coefficient on the interaction); the negative significant OLS coefficient in column 3 indicates that the negative supply effect of $H / L$ on employment in low-skill-intensive services seems to prevail (as it is contemplated in the model) when the effect of the demand shock is not isolated. As expected, due to the national nature of the demand for tradables, I find that an exogenous increase in skill intensity in one part of the tradable sector has no significant effect on employment in other parts of the tradable sector (columns 5 and 6). ${ }^{19}$

These results are consistent with Moretti (2010) who shows that an exogenous increase in the number of jobs in the tradable sector in a city results in an increase in local labor demand in the service sector, and that this effect is larger when

\footnotetext{
${ }^{19}$ The effect on the tradable sector is not necessarily zero but should be smaller than the one for the nontradable sector, and possibly even negative because the increase in wages generated by the initial shock hurts local producers of tradables.
} 
the exogenous increase in labor demand is concentrated among skilled workers. Relative to Moretti (2010) this paper adds the explicit account of consumption elasticities to the argument that positive demand shocks in the tradable sector have large multiplier effects on the nontradable sector.

In addition to the CEX-based evidence discussed in the previous section, the results presented here constitute a second piece of evidence in favor of a role of consumption elasticities in affecting the final demand of high-skill-intensive goods and services and through this channel also the demand for skills (i.e. the college premium).

\section{Quantification of the Demand Shift}

So far the evidence suggests that the consumption elasticity channel may contribute to the increase in the college premium, however neither the coefficients of Table 2 (at the aggregate economy level) nor of Table 4 (at the MSA level) are informative as to the extent to which an exogenous increase in education raises or decreases the overall demand for skilled labor. To answer this question, in this section I parametrize the relationship between the skill premium and the skill ratio implied by the model of Section I which for convenience I report again here:

$$
\frac{d \log w_{h}}{d \log H}=\frac{\left(1-a_{2}\right)\left\{\left(\lambda_{H}-\lambda_{L}\right)\left[R_{1}-\left(1-R_{1}\right) \frac{H}{L}\right]-\left[1+\lambda_{H}+\frac{H}{L}\left(1+\lambda_{L}\right)\right]\right\}}{\left(\lambda_{L}+1\right) \sigma+\left(\lambda_{H}-\lambda_{L}\right)\left(1-a_{1}\right) \sigma-\left(\lambda_{H}-\lambda_{L}\right) T}
$$

where $T=\left\{R_{1}\left[\varepsilon_{1 p}^{h}\left(a_{1}-a_{2}\right)+\varepsilon_{1 m}^{h}\left(1-a_{2}\right)\right]+\left(1-R_{1}\right)\left[\varepsilon_{1 p}^{l}\left(a_{1}-a_{2}\right)-a_{2} \varepsilon_{1 m}^{l}\right]\right\}$.

To bring the model to the data, I estimate income and price elasticities of two consumption aggregates from CEX data (the high-skill-intensive aggregate sums all 19 consumption items with skill ratio greater than 0.37 ) and labor market aggregates from CPS data. Table 5 summarizes the parameters' values for both the US and the UK. The details of the parameters' estimation are in the Appendix $\mathrm{A}$ at the end of the paper, in the following I describe the main results of the parametrization.

Filling in the relevant elasticities and labor market aggregates of the US economy of Table 5 in Equation 8, the final result is $\frac{d \log w_{h}}{d \log H}=-1.12$. This number must be compared to the counterfactual of what would have happened without the education and income effect in favor of high-skill-intensive consumption items. When solved with identical demand functions of skilled and unskilled consumers (i.e. $\left.y_{1}^{h}()=.y_{1}^{l}()=.y_{1}().\right)$ and homotheticity in income, the model of Section I gives the following counterfactual result (which is a two-sector version of the basic framework by Katz and Murphy, 1992):

$$
\frac{d \log w_{h}}{d \log H}=\frac{-\left(1-a_{2}\right)\left[1+\lambda_{H}+\frac{H}{L}\left(1+\lambda_{L}\right)\right]}{\left(\lambda_{L}+1\right) \sigma+\left(\lambda_{H}-\lambda_{L}\right)\left(1-a_{1}\right) \sigma-\left(\lambda_{H}-\lambda_{L}\right)\left[\varepsilon_{1 p}\left(a_{1}-a_{2}\right)+\frac{H}{H+L}-a_{2}\right]}
$$


TABle 5-Parameters of the Model

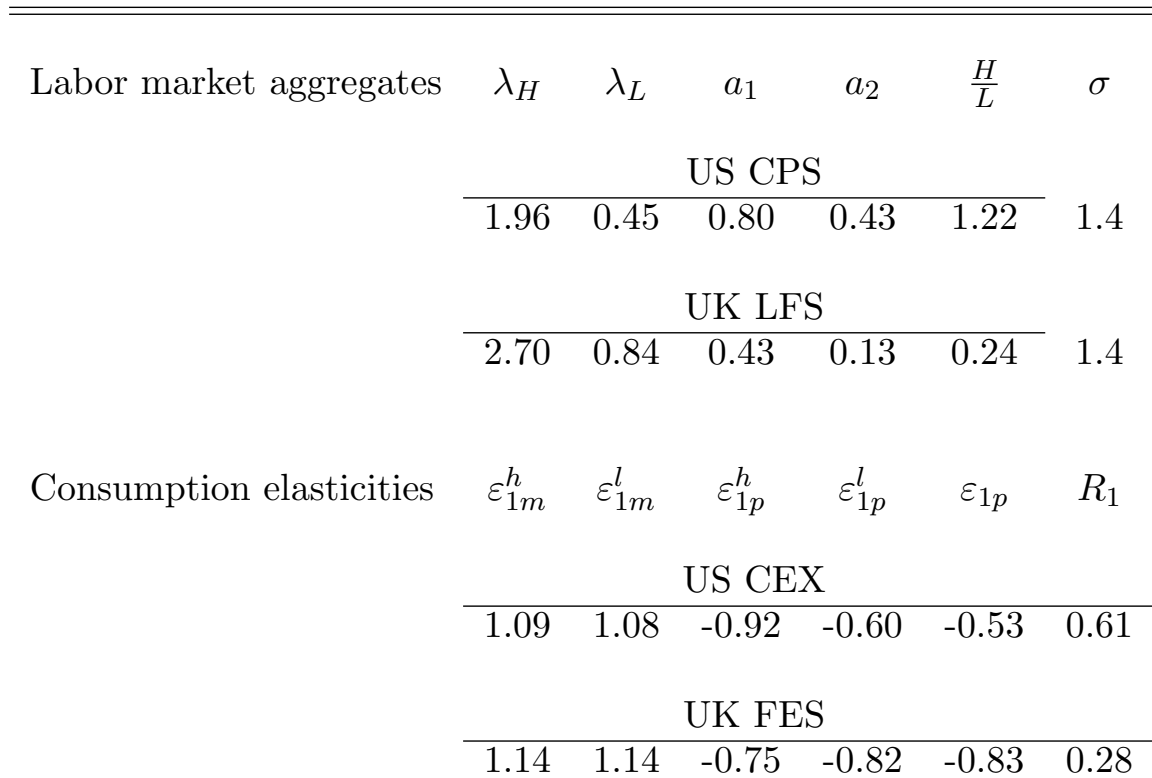

Note: $\lambda_{H}=\frac{H_{1}}{H_{2}}, \lambda_{L}=\frac{L_{1}}{L_{2}}, a_{1}=\frac{w_{h} H_{1}}{p_{1} y_{1}}, a_{2}=\frac{w_{h} H_{2}}{p_{2} y_{2}}$ and $\frac{H}{L}$ are estimated using CPS and LFS 1994 to 1997. $\varepsilon_{1 p}^{h}, \varepsilon_{1 p}^{l}, \varepsilon_{1 m}^{h}, \varepsilon_{1 m}^{l}, R_{1}$ are estimated using CEX and FES 1994 to 1997. $\sigma$ is from Katz and Murphy (1992).

whose parametrization yields $\frac{d \log w_{h}}{d \log H}=-1.22$.

The difference between Equation 8 and Equation 9 shows that education and income elasticities contribute to reduce the extent of the fall of $\frac{w_{h}}{w_{l}}$ in response to an increase in $\frac{H}{L}$ by 0.10 points $(1.22-1.12) .{ }^{20}$ To understand the magnitude of this contribution we need to relate it to the actual increase of the college premium in the US economy. The result of this exercise is summarized in Table 6 for both the US and the UK.

The actual skill ratio in the US economy $\frac{H}{L}$ increased by $66 \%$ between 1984 and 2002 and the college premium $\frac{w_{h}}{w_{l}}$ increased by $13 \%$ (CPS data, $H$ is some college or more). Equation 8 which incorporates the education and income effect in favor of skill-intensive consumption items implies that $\frac{w_{h}}{w_{l}}$ should have fallen by $74 \%(-1.12 * 0.66=-0.74$, see column 1 of Table 6$)$ as a result of an increase in $\frac{H}{L}$

\footnotetext{
${ }^{20}$ The total effect can be also decomposed in different parts. The direct effect of education elasticities can be quantified in $\left(1-a_{2}\right)\left(\lambda_{H}-\lambda_{L}\right)\left[R_{1}-\left(1-R_{1}\right) \frac{H}{L}\right]=0.11$ in the numerator of Equation 8 . In the denominator the effect through different price and income elasticities across skilled and unskilled workers can be quantified in the difference between $T=\left\{R_{1}\left[\varepsilon_{1 p}^{h}\left(a_{1}-a_{2}\right)+\varepsilon_{1 m}^{h}\left(1-a_{2}\right)\right]+\left(1-R_{1}\right)\left[\varepsilon_{1 p}^{l}\left(a_{1}-\right.\right.\right.$ $\left.\left.\left.a_{2}\right)-a_{2} \varepsilon_{1 m}^{l}\right]\right\}$ and $\varepsilon_{1 p}\left(a_{1}-a_{2}\right)$. The difference in income elasticities is calculated at $R_{1}\left(1-a_{2}\right) \varepsilon_{1 m}^{h}-$ $\left(1-R_{1}\right) a_{2} \varepsilon_{1 m}^{l}=0.20$. The difference in price elasticities is calculated at $R_{1}\left(a_{1}-a_{2}\right) \varepsilon_{1 p}^{h}+\left(1-R_{1}\right)\left(a_{1}-\right.$ $\left.a_{2}\right) \varepsilon_{1 p}^{l}-\left(a_{1}-a_{2}\right) \varepsilon_{1 p}=-0.016$.
} 
Table 6-Quantification of the Income and Education EfFects

\begin{tabular}{|c|c|c|c|c|c|}
\hline & $\begin{array}{c}\text { (1) } \\
\text { Model with } \\
\text { income and educ. } \\
\text { elasticities }\end{array}$ & $\begin{array}{c}(2) \\
\text { Model without } \\
\text { income and educ. } \\
\text { elasticities }\end{array}$ & $\begin{array}{c}(3) \\
\text { Difference } \\
(1)-(2)\end{array}$ & $\begin{array}{c}(4) \\
\text { Demand } \\
\text { shift } \frac{w_{h}}{w_{l}}\end{array}$ & $\begin{array}{c}(5) \\
\text { Contribution } \\
\text { of elasticities } \\
(3) /(4)\end{array}$ \\
\hline \multicolumn{6}{|l|}{ US CEX } \\
\hline $\begin{array}{l}\text { Implied } \frac{d \log w_{h}}{d \log H} \\
\text { Percentage terms }\end{array}$ & $\begin{array}{c}-1.12 \\
(-1.12 * 0.66)=-74 \%\end{array}$ & $\begin{array}{c}-1.22 \\
(-1.22 * 0.66)=-80 \%\end{array}$ & $6 \%$ & $80 \%+13 \%$ & $6.5 \%$ \\
\hline \multicolumn{6}{|l|}{ UK FES } \\
\hline $\begin{array}{l}\text { Implied } \frac{d \log w_{h}}{d \log H} \\
\text { Percentage terms }\end{array}$ & $\begin{aligned}-0.87 & \\
\left(-0.87^{*} 0.88\right) & =-77 \%\end{aligned}$ & $\begin{aligned}-0.97 & \\
\left(-0.97^{*} 0.88\right) & =-85 \%\end{aligned}$ & $8 \%$ & $85 \%+14 \%$ & $8 \%$ \\
\hline \multicolumn{6}{|c|}{$\begin{array}{l}\text { Note: The implied } \frac{d \log w_{h}}{d \log H} \text { are obtained parameterizing Equation } 8 \text { and Equation } 9 \text { using the parameters } \\
\text { of Table } 5 \text {. Percentage terms in column } 1 \text { and } 2 \text { are obtained multiplying the implied } \frac{d \log w_{h}}{d \log H} \text { by the } \\
\text { actual increase between } 1984-2002 \text { in } \frac{H}{L} \text { (in the US }=66 \% \text { and in the UK=88\%). The percentage terms } \\
\text { in column } 4 \text { are obtained summing the implied decrease of } \frac{w_{h}}{w_{l}} \text { along the relative demand curve of the } \\
\text { counterfactual model, i.e. the number in column } 2 \text {, to the actual increase between } 1984-2002 \text { in } \frac{w_{h}}{w_{l}}(\text { in } \\
\text { the US }=13 \% \text { and in the UK=14\%). }\end{array}$} \\
\hline
\end{tabular}

of $66 \%$. Equation 9 with identical preferences across educated and non-educated workers implies a fall of $\frac{w_{h}}{w_{l}}$ by $80 \%(-1.22 * 0.66=-0.80$, see column 2 of the table). This latter result implies that the total shift in relative labor demand is $93 \%$ : the actual $13 \%$ plus the counterfactual $80 \%$ implied by Equation 9 (column 4 of the table). Eventually the education and income elasticities in favor of skill-intensive consumption items reduce by $6 \%$ the fall of the relative wage $(74 \%$ instead of $80 \%$ ) and $6 \%$ points constitute about $6.5 \%$ of the $93 \%$ total shift in the relative labor demand (see column 5).

\section{A. Quantification of the Demand Shift for the UK}

As for the US, I estimating income and price elasticities of two consumption aggregates from FES data and labor market aggregates from LFS data. ${ }^{21}$ The result of the parametrization of Equation 8 is $\frac{d \log w_{h}}{d \log H}=-0.87$ while the parametrization of the counterfactual Equation 9 yields a result of -0.97 . In the UK the skill ratio $\frac{H}{L}$ increased by $88 \%$ between 1982 and 2000 and the college premium $\frac{w_{h}}{w_{l}}$ increased by $14 \%$ (LFS data). Equation 8 implies that the college premium should have

\footnotetext{
${ }^{21}$ Table 5 shows that while income and price elasticities are fairly similar across the US and UK, the value of $R_{1}=0.28$ which defines the education elasticity in the model is much lower in the UK. This is not surprising because the numerator of $R_{1}$ is the total expenditure on the 19 high-skill-intensive items by college-educated workers and the share of college-educated workers is much lower in the UK than in the US: $\frac{H}{L}=0.24$ in the LFS sample 1994-1997. Also the distribution of college-educated workers is much more concentrated in the skill-intensive industries in the UK rather than in the US: hence the higher value of $\lambda_{H}=\frac{H_{1}}{H_{2}}=2.7$ and the lower value of $\alpha_{2}=\frac{w_{h} H_{2}}{p_{2} y_{2}}=0.13$ in the UK with respect to the US.
} 
fallen by $77 \%\left(-0.87^{*} 0.88=-0.77\right.$, see column 1 of Table 6$)$ while counterfactual Equation 9 implies a fall of $85 \%\left(-0.97^{*} 0.88=-0.85\right.$, see column 2$)$ : a difference of $8 \%$. The total unexplained shift in relative labor demand in the UK is $99 \%$ (the actual $14 \%$ plus the counterfactual $85 \%$, see column 4) therefore education and income elasticities in favor of skill-intensive consumption items can account for around $8 \%$ of the total shift in the relative demand for skilled labor (see column $5)$.

\section{Conclusions}

The evidence presented in this paper shows that more educated (and richer) consumers not only consume more of the very low-skill-intensive services such as cleaning services and household services -as pointed out in Mazzolari and Ragusa (2013)- but also consume more of high-skill-intensive services such as education services, medical and professional services. The positive (and J-shaped) relationship between the education (and income) elasticities and the skill-intensity of consumption goods and services is evident both in the US and in the UK.

At the MSA level the positive relationship between the decadal changes in the share of skilled workers in the tradable sector in a city and the employment share of high-skill-intensive nontradable services, confirms that consumption changes based on education elasticities are likely to favor the demand for skill-intensive services.

The parametrization of a simple two-sector model suggests that overall the income and education effects in favor of skill-intensive goods and services can explain around $6.5 \%$ of the total increase in the college premium in the US from 1984 to 2002. Notwithstanding the differences between the US and UK in out of pocket expenditure in education and health services and in the share of collegeeducated workers, the overall results in terms of explanatory power are similar in the UK (8\%), which is an indication of the robustness of this simple model to parameter changes.

The mechanism based on education and income elasticities can give an additional contribution besides the traditional explanations based on technology or trade to the accounting of the increase in the college premium. Overall the product demand effect is not large - consistently with the findings of Autor and Dorn (2013) and Goos, Manning, and Salomons (2014) but also with the early literature on wage inequality which emphasized the role of within-industry shifts rather than between-industry shifts (Berman, Bound, and Machin 1998). However this mechanism is of great potential interest because of the stable structure of education (and income) elasticities over time which suggests a constant bias towards the demand for high-skill-intensive services (and to a lower extent for low-skill-intensive ones). This bias is also confirmed in the evolution over time of the shares of consumption of high-skill-intensive goods and services. 


\section{REFERENCES}

Acemoglu, Daron. 2002. "Technical Change, Inequality and the Labor Market." Journal of Economic Literature 40: 7-72.

Acemoglu, Daron, and David H. Autor. 2011. "Skills, Tasks and Technology: Implications for Employment and Earnings."In: Orley Ashenfelter and David Card, Editor(s), Handbook of Labor Economics, Elsevier, Volume 4B, 10431171.

Autor, David H., and David Dorn. 2013. "The Growth of Low-Skill Service Jobs and the Polarization of the US Labor Market." American Economic Review 103: 1553-1597.

Autor, David H., Lawrence F. Katz, and Melissa S. Kearney. 2006. "The Polarization of the US Labor Market." American Economic Review 96: 189-194.

Autor, David H., Lawrence F. Katz, and Melissa S. Kearney. 2008. "Trends in US Wage Inequality: Revising the Revisionists." Review of Economics and Statistics 90: 300-323.

Autor, David H., Frank Levy, and Richard J. Murnane. 2003. "The Skill Content of Recent Technological Change: An Empirical Investigation." Quarterly Journal of Economics 118: 1279-1333.

Berman, Eli, John Bound, and Zvi Griliches. 1994. "Changes in the Demand for Skilled Labor within U.S. Manufacturing: Evidence from the Annual Survey of Manufactures." Quarterly Journal of Economics 109: 367-397.

Berman, Eli, John Bound, and Steve Machin. 1998. "Implications of Skill-Biased Technical Change, International Evidence." Quarterly Journal of Economics 113: 1245-1280.

Black, Sandra, and Alexandra Spitz-Oener. 2010. "Explaining Women's Success: Technological Change and the Skill Content of Women's Work." Review of Economics and Statistics 92: 187-194.

Blundell, Richard, and Ben Etheridge. 2010. "Consumption, income and earnings inequality in Britain." Review of Economic Dynamics 13: 76-102.

Buera, Francisco J., and Joseph Kaboski. 2012. "The Rise of the Service Economy." American Economic Review 102: 2540-2569.

Card, David, and John DiNardo. 2002. "Skill biased technological change and rising wage inequality. Some problems and puzzles." Journal of Labor Economics 20: 733-83.

Clark, Colin. 1957. The Conditions of Economic Progress, MacMillan, London. Cortes, Patricia. 2008. "The Effect of Low-Skilled Immigration on US Prices: Evidence from CPI data." Journal of Political Economy 116: 381-422.

Cortes, Patricia, and Jose' Tessada. 2011. "Low-skilled Immigration and the Labor Supply of Highly Skilled Women." American Economic Journal: Applied Economics 3: 88-123. 
Dustmann, Christian, Johannes Ludsteck, and Uta Schönberg. 2009. "Revisiting the German Wage Structure." Quarterly Journal of Economics 124: 843-881.

Goldin, Claudia, and Lawrence Katz. 2007. The Race between Education and Technology. Harvard University Press, Boston.

Goos, Maarten, and Alan Manning. 2007. "Lousy and Lovely Jobs: the Rising Polarization of Work in Britain." Review of Economics and Statistics 89: 277282.

Goos, Maarten, Alan Manning, and Anna Salomons. 2009. "Job Polarization in Europe." American Economic Review Papers and Proceedings 99: 58-63.

Goos, Maarten, Alan Manning, and Anna Salomons. 2014. "Explaining Job Polarization: Routine-Biased Technological Change and Offshoring." forthcoming American Economic Review.

Heathcote, Jonathan, Fabrizio Perri, and Gianluca Violante. 2010. "Unequal we stand: An empirical analysis of economic inequality in the United States, 1967-2006." Review of Economic Dynamics 13: 15-51.

Katz, Lawrence F., and Kevin M. Murphy. 1992. "Changes in Relative Wages, 1963-1987: Supply and Demand Factors." Quarterly Journal of Economics 107: 35-78.

Lemieux, Thomas. 2006. "Post-Secondary Education and Increasing Wage Inequality." American Economic Review Papers and Proceedings 96: 1-23.

Leonardi, Marco. 2003. "Product Demand Shifts and Wage Inequality."IZA Discussion Paper 908.

Machin, Stephen, and John Van Reenen. 2008. "Wage Inequality, Changes in." In Durlauf S. N. and Blume L. E. (eds.) The New Palgrave Dictionary of Economics, Second edition, The New Palgrave Dictionary of Economics Online. Palgrave Macmillan

Manning, Alan. 2004. "We Can Work It Out: The Impact of Technological Change on the Demand for Low-Skill Workers." Scottish Journal of Political Economy 51: 581-608.

Mazzolari, Francesca, and Giuseppe Ragusa. 2013. "Spillovers from High-Skill Consumption to Low-Skill Labor Markets." Review of Economics and Statistics 95: 74-86.

Michaels, Guy, Ashwini Natraj, and John Van Reenen. 2014. "Has ICT Polarized Skill Demand?: Evidence from Eleven Countries over 25 Years." Review of Economics and Statistics 96: 60-77.

Moretti Enrico. 2010. "Local Multipliers." American Economic Review, Papers and Proceedings 100: 1-7.

Moretti Enrico. 2013. "Real Wage Inequality." American Economic Journal: Applied Economics 5: 65-103.

Ngai, Rachel L., and Christopher Pissarides. 2007. "Structural Change in a Multisector Model of Growth." American Economic Review 97: 429-443. 
Spitz-Oener, Alexandra. 2006. "Technical Change, Job Tasks and Rising Educational Demands: Looking Outside the Wage Structure." Journal of Labor Economics 24: 235-70.

Weiss, Matthias. 2008. "Skill-biased technological change: Is there hope for the unskilled?" Economics Letters 100: 440-442.

\section{Model Appendix}

Here I present the details of the model of Section I and the estimation strategy of the parameters reported in Table 5. The economy consists of $H$ skilled workers/consumers with a college degree and $L$ unskilled workers/consumers without a college degree. Let $Y_{1}=F_{1}\left(H_{1}, L_{1}\right)$ and $Y_{2}=F_{2}\left(H_{2}, L_{2}\right)$ denote the production functions of the high- and low-skill-intensive commodity respectively. The functions are assumed to be CES with elasticity of substitution $\sigma$. In this model there is no technical progress because the focus is on the role of product demand. For models that incorporate technical change see Autor, Levy, and Murnane (2003), Weiss (2008), Acemoglu and Autor (2011) and Autor and Dorn (2013). Labor markets are competitive and both labor inputs move across sectors to equate their marginal value. Since $Y_{1}$ is the high-skill-intensive commodity (or sector), it will have a larger skill intensity and a higher wage bill share of skilled labor i.e. if we define $a_{1}=\frac{w_{h} H_{1}}{p_{1} F_{1}(.)}$ and $a_{2}=\frac{w_{h} H_{2}}{p_{2} F_{2}(.)}$ the wage bill shares of skilled labor in the two sectors, and $\lambda_{H}=\frac{H_{1}}{H_{2}}$ and $\lambda_{L}=\frac{L_{1}}{L_{2}}$ the ratios of skilled and unskilled labor, by definition $a_{1}-a_{2}>0$ and $\lambda_{H}-\lambda_{L}>0$. The general equilibrium is completely described by the following five equations where the price of the low-skill-intensive commodity has been normalized to unity, $p_{2}=1$ :

$$
\begin{aligned}
p_{1} F_{1}\left(H_{1}, L_{1}\right) & =w_{l} L_{1}+w_{h} H_{1} \\
F_{2}\left(H-H_{1}, L-L_{1}\right) & =w_{l}\left(L-L_{1}\right)+w_{h}\left(H-H_{1}\right) \\
d \log \left(\frac{H_{1}}{L_{1}}\right) & =-\sigma d \log \left(\frac{w_{h}}{w_{l}}\right) \\
d \log \left(\frac{H-H_{1}}{L-L_{1}}\right) & =-\sigma d \log \left(\frac{w_{h}}{w_{l}}\right) \\
H y_{1}^{h}\left(p_{1}, w_{h}\right)+L y_{1}^{l}\left(p_{1}, w_{l}\right) & =F_{1}\left(H_{1}, L_{1}\right)
\end{aligned}
$$

The first two equations, A1 and A2, restate the constant returns assumption. Equations A3 and A4 are definitions of substitution elasticities in a CES technology. The last Equation A5 is the market equilibrium condition for commodity $Y_{1}$. According to Walras' law, equilibrium in the factors' market and in the market of commodity $Y_{1}$ implies that the market of commodity $Y_{2}$ clears. Taking the total 
differential and logs of equations A1-A5:

$$
\begin{array}{rr}
(\mathrm{A} 6) & d \log p_{1}=a_{1} d \log w_{h}+\left(1-a_{1}\right) d \log w_{l} \\
(\mathrm{~A} 7) & \left(1-a_{2}\right) d \log w_{l}=-a_{2} d \log w_{h} \\
\text { (A8) } & \begin{array}{r}
d \log H_{1}-d \log L_{1}=-\sigma\left(d \log w_{h}-d \log w_{l}\right) \\
\text { (A9) } \\
\left(1+\lambda_{H}\right) d \log H-\lambda_{H} d \log H_{1}-\left(1+\lambda_{L}\right) d \log L+\lambda_{L} d \log L_{1}= \\
=-\sigma\left(d \log w_{h}-d \log w_{l}\right) \\
(\mathrm{A} 10) \\
R_{1}\left[\varepsilon_{1 p}^{h} d \log p_{1}+\varepsilon_{1 m}^{h} d \log w_{h}+d \log H\right]+ \\
\left(1-R_{1}\right)\left[d \log L+\varepsilon_{1 p}^{l} d \log p_{1}+\varepsilon_{1 m}^{l} d \log w_{l}\right]=a_{1} d \log H_{1}+\left(1-a_{1}\right) d \log L_{1}
\end{array}
\end{array}
$$

Assuming total labor supply is fixed i.e. $d H=-d L$, substituting equations A6 to A9 in A10 we obtain:

$$
\frac{d \log w_{h}}{d \log H}=\frac{\left(1-a_{2}\right)\left\{\left(\lambda_{H}-\lambda_{L}\right)\left[R_{1}-\left(1-R_{1}\right) \frac{H}{L}\right]-\left[1+\lambda_{H}+\frac{H}{L}\left(1+\lambda_{L}\right)\right]\right\}}{\left(\lambda_{L}+1\right) \sigma+\left(\lambda_{H}-\lambda_{L}\right)\left(1-a_{1}\right) \sigma-\left(\lambda_{H}-\lambda_{L}\right) T}
$$

where $T=\left\{R_{1}\left[\varepsilon_{1 p}^{h}\left(a_{1}-a_{2}\right)+\varepsilon_{1 m}^{h}\left(1-a_{2}\right)\right]+\left(1-R_{1}\right)\left[\varepsilon_{1 p}^{l}\left(a_{1}-a_{2}\right)-a_{2} \varepsilon_{1 m}^{l}\right]\right\} .{ }^{22}$ The parameters of the equation above (which are reported in Table 5) are estimated in the following way. To match the two-sector nature of the model, the 38 consumption items and the corresponding industries in Table 1 in the paper are divided in two aggregate consumption items and two aggregate production sectors. The high-skill-intensive (low-skill-intensive) aggregate consumption item is the sum of the expenditure shares in the 19 high-skill-intensive (low-skill-intensive) consumption items. The high-skill-intensive (low-skill-intensive) aggregate production sector is the sum of the number of workers in the 19 high-skill-intensive (low-skill-intensive) production sectors. Parameters estimated from the CPS sample 1994-1997: $\lambda_{H}=\frac{H_{1}}{H_{2}}=1.96\left(\lambda_{L}=\frac{L_{1}}{L_{2}}=0.45\right)$ is the sum of the number of workers with (without) some college education who work in the 19 high-skillintensive industries divided by those who work in the 19 low-skill-intensive industries. The wage bill share of workers with some college education in the 19 high-skill-intensive industries is $\alpha_{1}=\frac{w_{h} H_{1}}{p_{1} y_{1}}=0.80$; in the 19 low-skill-intensive industries it is $\alpha_{2}=\frac{w_{h} H_{2}}{p_{2} y_{2}}=0.43 .^{23}$ The skill ratio is $\frac{H}{L}=1.22$. Parameters estimated from the CEX sample 1994-1997: the education elasticity is defined by $R_{1}$ which is the share of expenditure on the skill-intensive aggregate consump-

\footnotetext{
${ }^{22}$ The relationship between $\frac{w_{h}}{w_{l}}$ and $\frac{H}{L}$ depends on substitution elasticities in the production function and on price and income elasticities of demand for high-skill-intensive goods which in turn reflect elasticities of substitution of high-skill-intensive and low-skill-intensive goods in consumption. Obviously factors should not be perfect substitutes in production $\left(\sigma_{i} \neq \infty\right)$ nor goods should be perfect substitutes in consumption $\left(\varepsilon_{1 p}^{i} \neq \infty\right)$.

${ }^{23} a_{1}$ and $a_{2}$ are calculated assuming constant returns to scale i.e. $p_{1} y_{1}=w_{l} L_{1}+w_{h} H_{1}$ and $p_{2} y_{2}=$ $w_{l} L_{2}+w_{h} H_{2}$. The value of production in the high-skill and in the low-skill-intensive sector is calculated summing the wages of all workers in that sector.
} 
tion item by college-educated workers: $R_{1}=\frac{H y_{1}^{h}(.)}{H y_{1}^{h}(.)+L y_{1}^{l}(.)}=0.61$ (which is higher than the share of educated workers $\frac{H}{H+L}=0.55$ and therefore increases inequality in the model). Due to the normalization in the model with respect to the low skill sector, the elasticities $\varepsilon_{1 m}^{i}$ and $\varepsilon_{1 p}^{i}$ (where $i$ is the education group) are expressed in relative terms and they refer to consumption of the high-skill-intensive aggregate good relative to the low-skill-intensive good. The estimation takes into account a system of two equations and the constraints imposed by the theory:

$$
\begin{aligned}
& \omega_{1 i}=\gamma_{1} \mathbf{X}_{i}^{\prime}+\beta_{1} \log x_{i}+\theta_{1} \log \left(\frac{p_{1}}{p_{2}}\right)+\zeta_{1}+\varepsilon_{1 i} \\
& \omega_{2 i}=\gamma_{2} \mathbf{X}_{i}^{\prime}+\beta_{2} \log x_{i}+\theta_{2} \log \left(\frac{p_{1}}{p_{2}}\right)+\zeta_{2}+\varepsilon_{2 i}
\end{aligned}
$$

where $\omega_{1 i}$ indicates the sum of the expenditure shares by household $i$ on the 19 high-skill-intensive items produced in sector 1 and $\omega_{2 i}$ the sum of the expenditure shares on the 19 low-skill-intensive items produced in sector $2 ; \log x_{i}$ is $\log$ total expenditure for household $i$ deflated by the CPI and $\mathbf{X}_{i}$ contains age and sex of the head and the number of children in the household. Prices are aggregated using the weighted geometric mean (Stone price index) over prices which have been normalized to one: $\log p_{1}=\sum_{j=1}^{19} w_{j} \log p_{j}$ is an aggregate price index constructed using the individual commodity price series $\log p_{j}$ of the 19 high-skill-intensive items and their annual shares in total expenditure $w_{j}$ as weights (the same holds for $\log p_{2}$ and the 19 low-skill-intensive items). The standard errors are clustered at the household level. The system A12 is estimated stacking the two equations in a fixed effect regression and imposing the homogeneity and symmetry constraints. To be consistent with a demand system $\sum\left(\omega_{1 i}+\omega_{2 i}\right)=1$, the following restrictions are imposed: $\zeta_{1}+\zeta_{2}=1, \gamma_{1}+\gamma_{2}=0, \beta_{1}+\beta_{2}=0$ (homogeneity in income) and $\theta_{1}+\theta_{2}=0$ (homogeneity and symmetry in prices coincide given that there is a single relative price index). Two separate systems are estimated to calculate income elasticities of households with skilled and unskilled heads. The income (price) elasticities reported in Table 5 are calculated at the average household characteristics and are equal to $\varepsilon_{1 m}=\frac{\widehat{\beta}_{1}}{\bar{\omega}}+1\left(\varepsilon_{1 p}=\frac{\widehat{\theta}_{1}}{\bar{\omega}}-1\right)$ where $\bar{\omega}$ is the average expenditure share. To calculate income and price elasticities of skilled workers, I use $\bar{\omega}, \widehat{\beta}_{1}, \widehat{\theta}_{1}$ of the sample of workers with some-college education; to calculate the elasticities of unskilled workers I use the corresponding parameters of the sample of workers without college education. Consistently with the predictions of the model income elasticities of the skill-intensive aggregate are higher than one for both education groups and both the US and UK. 